\title{
Новые металл-ионообменные нанокомпозиты для удаления молекулярного кислорода из воды
}

\author{
Крысанов В.А., Плотникова Н.В., Кравченко Т.А., Окушко А.И. \\ ФБГОУ ВО «Воронежский государственный университет», Воронеж
}

Поступила в редакцию 31.07.2017 г.

\begin{abstract}
Методом химического осаждения синтезированы новые нанокомпозиты медьсульфокатионообменная матрица Lewatit SP-112 H и Lewatit K 2620. Полученные материалы отличаются изопористой структурой и монодисперсным распределением частиц меди по размеру. В химическом отношении синтезированные нанокомпозиты показывают более высокие скорости поглощения кислорода при однократном осаждении меди и практически одинаковые параметры при пятикратном осаждении, а также характеризуются большей воспроизводимостью кинетических данных по сравнению с аналогом КУ-23, что позволяет отнести их к высокоэффективным нанокомпозитным материалам для глубокого удаления молекулярного кислорода из воды.
\end{abstract}

Ключевые слова: нанокомпозит, наночастицы, металл, ионообменник, кислород, обескислороживание.

\section{New metal-ion-exchange nanocomposites to remove molecular oxygen from water}

\author{
Krysanov V.A., Plotnikova N.V., Kravchenko T.A., Okushko A.I. \\ Voronezh State University, Voronezh
}

Synthesis of a nanocomposites starts with an ionic polymer with ion exchanging capability which is then chemically treated with an ionic salt solution of a metal and then chemically reduced to yield ionic polymer metal composites. The ion exchange capacity was determined by the chemical decomposition of the metal and then by the method of complexometric titration of the copper salt solution. Several widely used material science techniques are applicable for the characterization of the $\mathrm{Cu}$ nanoparticles. They include $\mathrm{X}$ ray diffraction (XRD) and scanning electron microscopy (SEM). The kinetics was studied with gasometrical equipment.

The obtained «Lewatit» nanocomposites with a copper content equivalent to one and five cycles of metal deposition have an increased copper content compared to the KU-23 analogue, due to the high ion exchange capacity of hydrogen. According to XRD-analysis, all samples have a similar size of copper nanoparticles, SEM-analysis shows smaller copper agglomerates for samples with a «Lewatit» matrix, in comparison with «KU-23». It is shown, that at one cycle of metal deposition, «Lewatit» materials absorb large volumes of oxygen dissolved in water, and at five cycles of metal deposition, the differences are insignificant.

We demonstrate that the properties of the hybrid material depend on the nature of matrix and it properties as well as on the size of the nanoparticle dispersed within. Due to the high ion-exchange capacity, «Lewatit» nanocomposites contain high amounts of copper. The microscopy analysis shows, that the size of the nanocrystallites is smaller for the above composites. The combined effect of these factors has an impact on the high effectiveness of «Lewatit» materials for oxygen removal.

Keywords: Nanocomposite, nanoparticles, metal, ion exchanger, oxygen, oxygen removal. 


\section{Введение}

Потребность в ультрачистой воде со временем только растет, и традиционные физические и химические методы очистки воды постепенно уступают место более инновационным технологиям, позволяющим проводить глубокое, но в то же время беспримесное удаление кислорода [1].

Развитие ионообменных технологий и появление широкого ассортимента ионообменных смол сделало их наиболее используемыми в процессах водоподготовки и обескислороживании. Для технологии каталитического удаления кислорода из воды применяют смолы Lewatit K 3433 и Lewatit K 7333 (Германия), допированные палладием [2,3]. В технологиях, запатентованных фирмой «Вауег» (Германия), для деоксигенации используют смолу Lewatit MP 62 WS [4]. В технологии [5] нашел применение высокоосновной анионообменник АМ гелевой структуры (Россия). В [6, 7] запатентованы устройства и материалы для глубокого обескислороживания воды в замкнутой системе, основным материалом которой служат нанокомпозиты на основе ионообменника КУ-23 (Украина).

Ионообменные матрицы и осажденные в них частицы металлов нанокомпозитов различаются емкостью по функциональным центрам (противоионам и металлическому компоненту) и структурной организацией (размером и распределением пор и частиц металла по размерам и по грануле).

Задачей настоящей работы явилось выяснение роли ионообменных и размерно-структурных факторов в процессе сорбции молекулярного кислорода, растворенного в воде, новыми синтезированными нанокомпозитными материалами медьионообменник $\mathrm{Cu} \cdot$ Lewatit SP-112H $\left(\mathrm{H}^{+}\right)$и $\mathrm{Cu} \cdot$ Lewatit $\mathrm{K} 2620\left(\mathrm{H}^{+}\right)$для обескислороживания воды.

\section{Эксперимент}

Синтез нанокомпозитов $\mathrm{Cu} \cdot$ Lewatit SP-112H $\left(\mathrm{H}^{+}\right)$и $\mathrm{Cu} \cdot$ Lewatit $\mathrm{K} 2620\left(\mathrm{H}^{+}\right)$ проводили по известной методике ионообменного насыщения и химического осаждения металла [8]. Содержание металла в образцах соответствует 1 и 5 циклам осаждения. Ранее [9] было установлено, что при пяти циклах осаждения меди эффективность восстановления кислорода нанокомпозитом достигает максимальных значений вследствие преодоления порога перколляции электронной проводимости. Окислительно-восстановительную ёмкость по меди определяли методом титрования раствора с химически растворенным металлом [10].

Сравнение физико-химических характеристик ионообменных смол Lewatit проводили относительно ионообменника КУ-23 (табл.1.).

Таблица 1. Основные физико-химические характеристики ионообменных смол

\begin{tabular}{|c|c|c|c|}
\hline Характеристики & $\mathrm{KУ}-23$ & Lewatit $\mathrm{SP}-112 \mathrm{H}$ & Lewatit $\mathrm{K} 2620$ \\
\hline Функциональные группы & $\mathrm{R}-\mathrm{SO}_{3}^{-} \mathrm{H}^{+}$ & $\mathrm{R}-\mathrm{SO}_{3}^{-} \mathrm{H}^{+}$ & $\mathrm{R}-\mathrm{SO}_{3}^{-} \mathrm{H}^{+}$ \\
\hline Размер гранул $d$, мм & $0.1-0.5$ & 0.6 & $0.4-0.6$ \\
\hline Площадь поверхности, ${ }^{2} / \Gamma$ & $30-40$ & 30 & 33 \\
\hline Пористость & \multicolumn{3}{|c|}{ Макропористые } \\
\hline Размер пор, нм & $10-100$ & 33 & 41 \\
\hline $\begin{array}{c}\text { Ионообменная ёмкость } \varepsilon_{H^{+}}, \\
\text {мэкв/см}\end{array}$ & 1.2 & 1.6 & 1.9 \\
\hline
\end{tabular}

Крысанов и др. / Сорбционные и хроматографические процессы. 2017. Т. 17. № 5 
Размеры и радиальное распределение частиц меди в зерне оценивали по данным рентгенографического анализа (РФА), полученным на рентгеновском дифрактометре Thermo ARL X'TRA (Швейцария), и сканирующей электронной микроскопии (CЭМ), полученным на электронном микроскопе JSM-6380LV (Япония). Оценка эффективности созданных материалов проводилась по результатам исследования скорости поглощения молекулярного кислорода, растворенного в воде при температуре $20 \pm 1^{\circ} \mathrm{C}$. Кинетические испытания нанокомпозита проводили в газометрической ячейке с водой, содержащей растворенный кислород с постоянной концентрацией 26.2 мг/дм ${ }^{3}[10]$.

\section{Обсуждение результатов}

На рис.1. приведены микрофотографии поверхностей срезов зерен НК для разных матриц, полученные методом сканирующей электронной микроскопии. После статистической обработки полученных СЭМ - изображений были построены гистограммы распределения частиц меди по размерам для каждого образца с 1 и 5 циклами осаждения металла (рис.2). Также методом рентгенографического анализа определили средний размер частиц для всех исследуемых образцов. Полученные физико-химические характеристики для композитов с различным числом циклов осаждения меди $(\mathrm{N})$, на трех ионообменных матрицах, приведены в табл. 2. Из таблицы видно значительное расхождение в размерах частиц металла, определенных методами РФА и СЭМ, связанное с тем, что метод сканирующей микроскопии обнаруживает агломераты частиц, а метод РФА чувствителен к частицам, в которых реализуется «дальний порядок» [11].
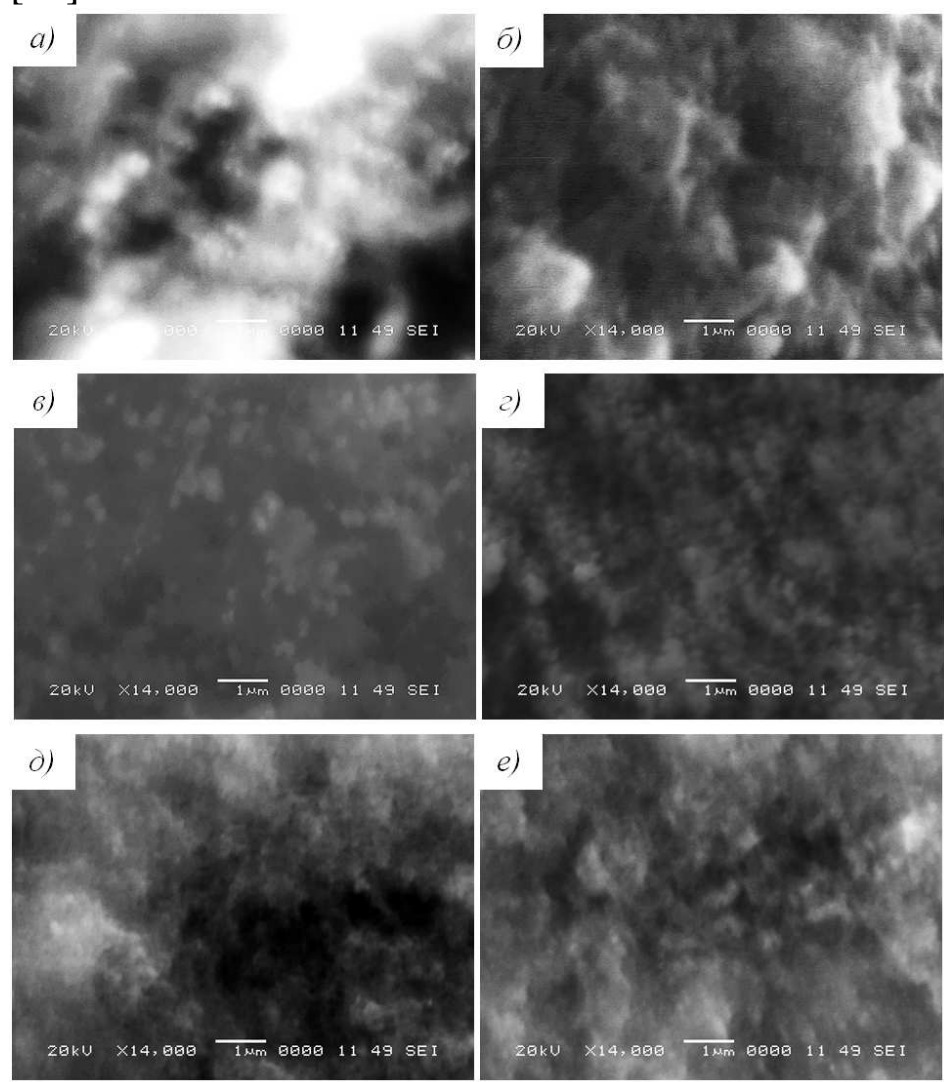

Рис. 1. Микрофотографии образцов: $\mathrm{Cu} \cdot \mathrm{KУ}-23\left(\mathrm{H}^{+}\right)-a$, $\sigma$; $\mathrm{Cu} \cdot$ Lewatit SP-112H $\left(\mathrm{H}^{+}\right)-6,2 ; \mathrm{Cu} \cdot$ Lewatit $\mathrm{K} 2620\left(\mathrm{H}^{+}\right)-\partial, e ; \mathrm{N}=1-a, c, \partial ; \mathrm{N}=5-\sigma$, г, $e$. 
Таблица 2. Физико-химические характеристики синтезированных нанокомпозитов

\begin{tabular}{|c|c|c|c|c|c|c|}
\hline \multirow{3}{*}{$\begin{array}{c}\text { Параметр } \\
\text { Метод } \\
N \text { циклов } \\
\text { осаждения }\end{array}$} & \multirow{2}{*}{\multicolumn{2}{|c|}{$\begin{array}{c}\text { Емкость } \varepsilon_{\mathrm{Cu}} \text { мэкв } / \mathrm{cm}^{3} \text { насып- } \\
\text { ной массы НК } \\
\text { Титрование }\end{array}$}} & \multicolumn{4}{|c|}{ Размер частиц металла, $d$ нм } \\
\hline & & & & & & \\
\hline & 1 & 5 & 1 & 5 & 1 & 5 \\
\hline $\mathrm{Cu} \cdot \mathrm{KY}-23$ & $1.14 \pm 0.03$ & $5.08 \pm 0.02$ & $31 \pm 2$ & $31 \pm 3$ & $400 \pm 100$ & $500 \pm 200$ \\
\hline $\begin{array}{c}\mathrm{Cu} \cdot \text { Lewatit SP- } \\
112 \mathrm{H}\end{array}$ & $1.18 \pm 0.04$ & $5.38 \pm 0.03$ & $30 \pm 2$ & $38 \pm 2$ & $250 \pm 50$ & $250 \pm 50$ \\
\hline $\begin{array}{cc}\text { Cu.Lewatit } & K \\
2620 & \end{array}$ & $1.28 \pm 0.01$ & $5.58 \pm 0.11$ & $29 \pm 2$ & $42 \pm 2$ & $350 \pm 150$ & $400 \pm 100$ \\
\hline
\end{tabular}
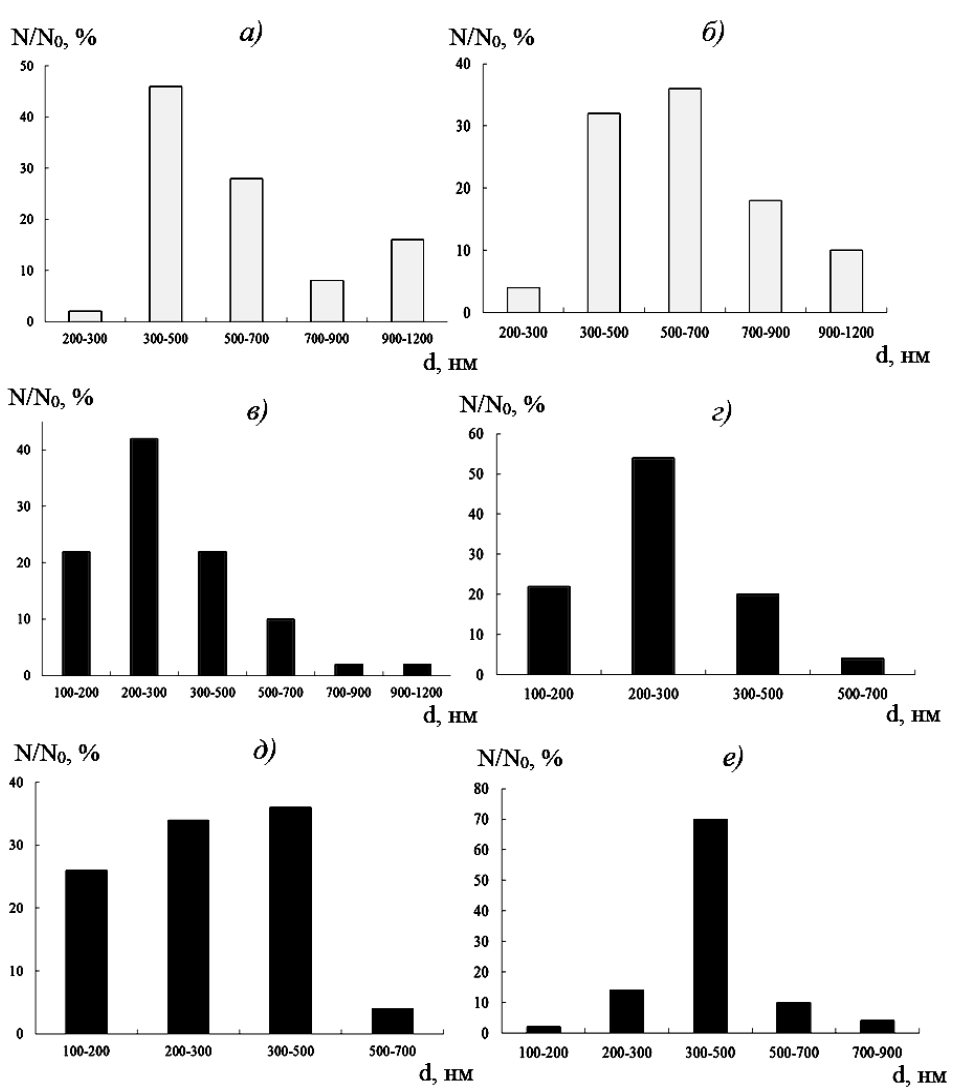

Рис. 2. Гистограммы распределения частиц по размерам: $\mathrm{Cu} \cdot \mathrm{KУ}-23\left(\mathrm{H}^{+}\right)-a, \sigma$; $\mathrm{Cu} \cdot$ Lewatit SP-112H $\left(\mathrm{H}^{+}\right)-6,2 ; \mathrm{Cu} \cdot$ Lewatit $\mathrm{K} 2620\left(\mathrm{H}^{+}\right)-\partial, e ; \mathrm{N}=1-a, c, \partial ; \mathrm{N}=5-6$, , $e$.

При переходе от 1 к 5 циклам осаждения меди по данным СЭМ наблюдается некоторое укрупнение агломератов для матриц КУ-23 и Lewatit K 2620, исключением является ионообменная основа Lewatit SP-112H. Самые крупные агломераты меди обнаружены для образца с матрицей КУ-23, что вероятно связано с широким разбросом размеров пор матрицы. Однако, метод РФА не выявил изменения размера частиц металла при увеличении числа циклов осаждения меди для образцов на основе КУ-23 и обнаружил увеличение размера кристаллитов меди в Lewatit SP-112H и Lewatit K 2620 на 25-30\%. Можно предположить, что это связано с меньшей доступностью пор на матрицах Lewatit, поэтому с увеличением циклов осаждения преимущественно идет процесс укрупнения имеющихся кристаллитов, а не образования новых. Для 1 цикла осаждения меди образцы на основах Lewatit SP-112H и Lewatit K 2620 обладают меньшим размером металлических образований и в отличие от матрицы КУ-23 являются монопористыми полимерами. 
По данным элементного анализа были построены кривые радиального распределения меди в образцах с разными матрицами и разным содержанием металла (рис. 3). Отмечается схожая тенденция повышения содержания меди от центра к периферии зерна для всех матриц. Однако следует указать, что для высокоемкого $\mathrm{Cu} \cdot$ Lewatit K $2620\left(\mathrm{H}^{+}\right)$наблюдается преимущественно поверхностное распределение меди.

Макропористые смолы Lewatit обладают повышенной ионообменной емкостью по сравнению с КУ-23. Соответственно емкость осажденной меди несколько выше при одинаковом числе циклов осаждения меди.

Оценка кинетики поглощения кислорода на синтезированных нанокомпозитах проводилась на основе исследования зависимостей объема и степени поглощения кислорода по отношению к емкости по металлическому компоненту от времени эксперимента (рис.4). Сравнение кинетических кривых для трех образцов показало достаточно высокую эффективность материалов на основе матриц Lewatit SP-112H и Lewatit K 2620, не уступающих, а на начальном этапе для нанокомпозита Cu-Lewatit $\mathrm{SP}-112 \mathrm{H}\left(\mathrm{H}^{+}\right)$даже превосходящую нанокомпозит $\mathrm{Cu} \cdot \mathrm{KУ}-23\left(\mathrm{H}^{+}\right)$по скорости и степени поглощения растворенного в воде кислорода.

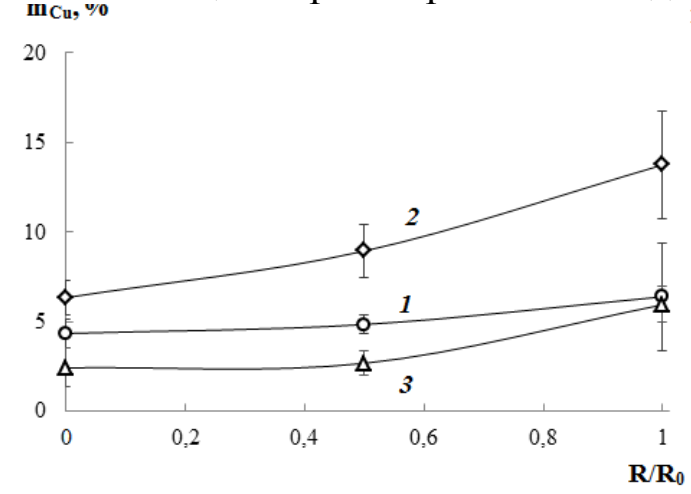

a

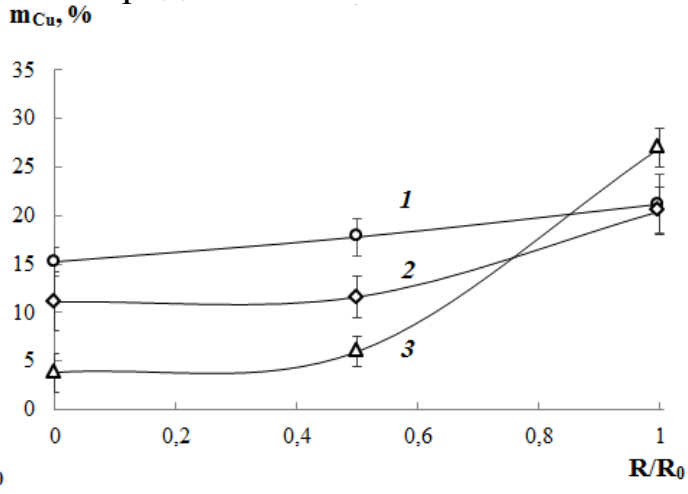

6

Рис. 3. Кривые радиального распределения меди в зернах НК:

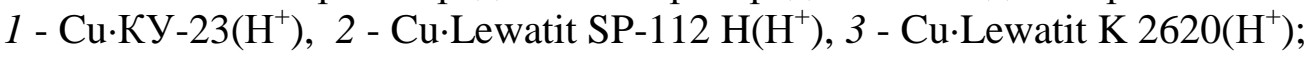
a) $\mathrm{N}=1$, б) $\mathrm{N}=5$
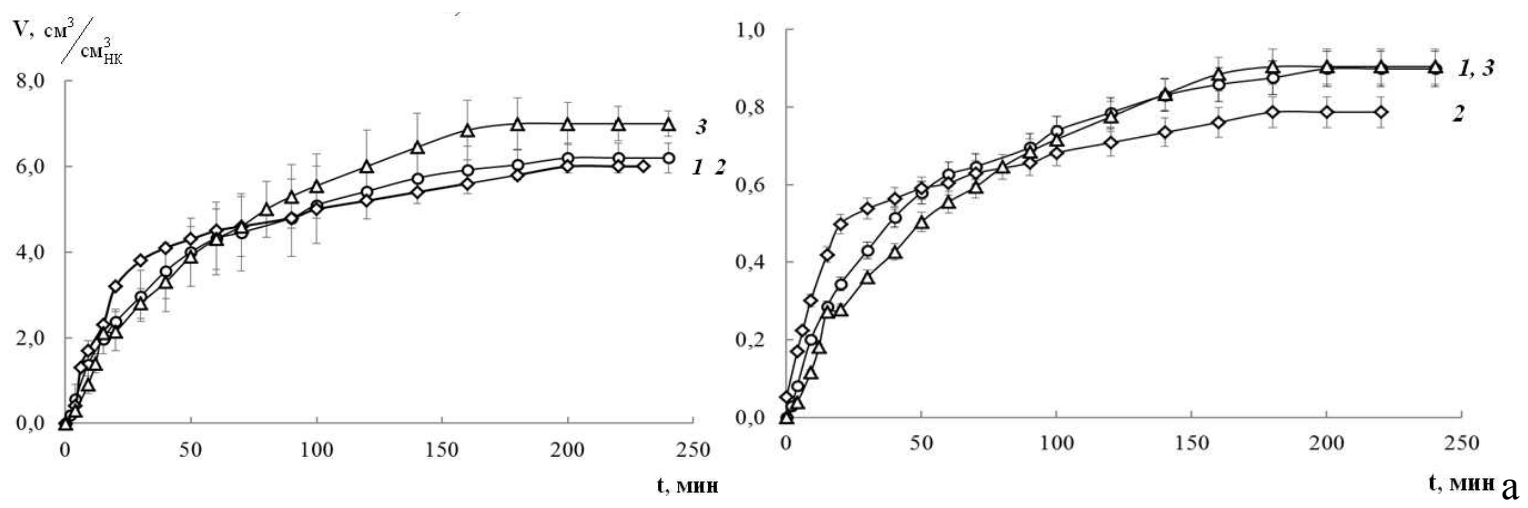

6

Рис. 4. Объем $V$ поглощённого кислорода $a$ ) и степень полноты $\alpha$ восстановления кислорода из воды $\sigma$ ) в зависимости от времени $t$ нанокомпозитами 1 - $\mathrm{Cu} \cdot \mathrm{KY}-23\left(\mathrm{H}^{+}\right), 2$ - Cu-Lewatit SP-112 $\mathrm{H}\left(\mathrm{H}^{+}\right), 3$ - Cu-Lewatit $\mathrm{K} 2620\left(\mathrm{H}^{+}\right)$; $\varepsilon_{C u}=1.02-1.34$ мэкв/ $\mathrm{cm}^{3}$. 
Сравнительный анализ кинетики восстановления кислорода на высокоемких нанокомпозитах медь - ионообменник выявил, что по скорости и степени поглощения кислорода все исследованные нанокомпозиты ведут себя практически одинаково (рис. 5). Расхождения по скорости и степени поглощения кислорода не превышают 6-8\%. Некоторое уменьшение степени сорбции при длительном времени эксперимента для нанокомпозитов $\mathrm{Cu}$.Lewatit также может быть связано с меньшей доступностью пор и несколько большим содержанием меди на поверхности для матрицы Lewatit K $2620\left(\mathrm{H}^{+}\right)$.

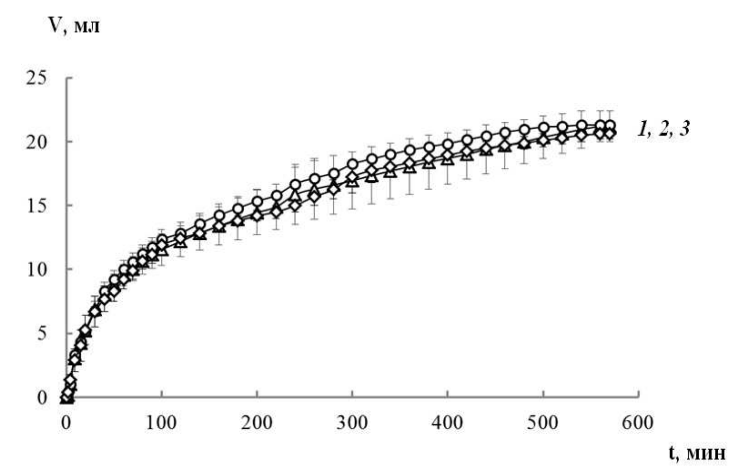

a

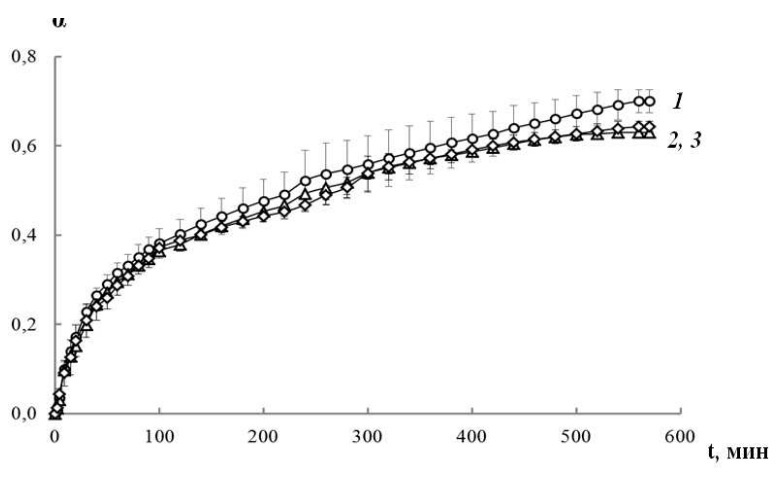

6

Рис. 5. Объем $V$ поглощённого кислорода $a$ ) и степень полноты $\alpha$ восстановления кислорода из воды б) в зависимости от времени $t$ нанокомпозитами:

1 - Cu-KУ-23( $\left.\mathrm{H}^{+}\right), 2$ - Cu-Lewatit SP-112 $\mathrm{H}\left(\mathrm{H}^{+}\right), 3$ - $\mathrm{Cu} \cdot$ Lewatit

Процесс окисления медьсодержащего нанокомпозита в $\mathrm{H}^{+}$- ионной форме, когда его частицы и противоионы матрицы находятся в эквивалентном соотношении, протекает с образованием растворимых продуктов окисления меди [10]:

$$
\left[\mathrm{R}-\mathrm{SO}_{3}^{-} \mathrm{H}^{+}\right]_{2} \cdot \mathrm{Cu}^{0}+1 / 2 \mathrm{O}_{2}=\left(\mathrm{R}-\mathrm{SO}_{3}^{-}\right)_{2} \mathrm{Cu}^{2+}+\mathrm{H}_{2} \mathrm{O}
$$

При сверхэквивалентном содержании металла в нанокомпозите в ходе восстановления кислорода образуются в основном нерастворимые продукты меди.

На интенсивность процесса, протекающего на основах Lewatit, влияет высокая обменная ёмкость композитов по ионам водорода и частицам меди, а также наименьший размер агломератов меди в Lewatit K 2620. Кроме того, с технической и экономической точки зрения, высокая ёмкость по металлу на композитах Lewatit достигается за меньшее количество циклов осаждения, благодаря высокой обменной емкости по водороду. Высокоемкие нанокомпозиты, полученные на ионообменных основаx Lewatit, имеют размеры кристаллитов, практически совпадающие с размером пор полимерной матрицы (табл. 1 и 2), в отличие от нанокомпозита на основе КУ-23, поры которого не фиксированы. Это приводит к увеличению воспроизводимости кинетики поглощения кислорода на них и сокращению величины доверительного интервала по сравнению с кривой для $\mathrm{Cu} \cdot \mathrm{KУ}-23\left(\mathrm{H}^{+}\right)$почти в два раза. Преимущества синтезированных материалов позволили выделить их в качестве новых запатентованных материалов для глубокого удаления растворенного в воде кислорода [12].

В $[10,13]$ показано, что при относительно малых изменениях в размере частиц металла наибольшее ускоряющее воздействие на процесс будет оказывать неравномерность радиального их распределения. Влияние этого фактора, помимо увеличения площади контакта реагирующих веществ, обусловлено сокращением длины диффузионного пути молекул кислорода к месту реакции. Рост содержания металла 
от одного до пяти циклов осаждения нивелирует различия в кинетических свойствах нанокомпозитах с различными ионообменными матрицами.

\section{Заключение}

Синтезированы высокоэффективные композитные наноматериалы для глубокого удаления кислорода из водных растворов посредством ионообменного насыщения и химического осаждения наночастиц меди в ионообменные основы Lewatit K 2620 и Lewatit SP-112 Н. Полученные материалы отличаются повышенным содержанием металлического компонента, изопористой структурой и монодисперсным распределением частиц меди по размеру. В химическом отношении синтезированные нанокомпозиты показывают более высокие скорости восстановления поглощенного кислорода при однократном осаждении меди и практически одинаковые параметры при пятикратном осаждении металла, а также характеризуются более высокой воспроизводимостью кинетики поглощения кислорода на них по сравнению с аналогом КУ-23.

Работа выполнена при финансовой поддержке Российского фонда фундаментальных исследований (код проекта № 17-08-00426_а) и Министерства науки и образования РФ в рамках госзадания вузам на 2014-2016 г2. (проект № 675).

Результаты микроскопических исследований получены на оборудовании ЦКП НО ВГУ.

\section{Список литературы}

1. Волков В.В., Кравченко Т.А., Ролдугин В.И. // Успехи химии. 2013. Т.82. № 5. С. 465482.

2. Product information Lewatit K3433. Peжим доступа: http://www.lenntech.com/Datasheets/Lewatit-K-3433-L.pdf (дата обращения: 26.06.2017).

3. Product information Lewatit K 7333. Peжим доступа: http://www.lenntech.com/Datasheets/Lewatit-K-7333-L.pdf (дата обращения: 26.06.2017).

4. Product information Lewatit MP 62 WS. Режим доступа: http://www.lenntech.com/Data-sheets/LewatitMP-62-WS-L.pdf (дата обращения: 26.06.2017).

5. Кудрявцев В.В. Патент РФ. № 2217382.2003

\section{References}

1. Volkov V.V., Kravchenko N.A., Roldugin V.I., Russian Chemical Reviews, 2013, Vol. 82, No 5, pp. 465-482.

2. Product information Lewatit K3433. Available at: http://www.lenntech.com/Data-
6. Полянский Л.Н. Патент РФ. № 105284. 2011.

7. Полянский Л.Н. Патент РФ. № 134527. 2013.

8. Крысанов В.А. Патент РФ. № 2355471. 2009.

9. Хорольская С.В. // Журнал физической химии. 2014. Т. 88. № 5. С. 1-8

10.Кравченко Т.А., Полянский Л.Н., Калиничев А.И. и др. Нанокомпозиты металлионообменник. М. Наука. 2009. 391 с.

11. Skoog D.A., Holler F. J., Nieman T. A. Principles of instrumental analysis. USA, Saunders College Pub. 1998. p. 1040.

12. Крысанов В.А. Патент РФ. № 172363. 2017.

13. Киприянова Е.С., Кравченко Т.А., Конев Д.В. // Журнал физической химии. 2010. Т. 84. № 6. C.1104.
sheets/Lewatit-K-3433-L.pdf (accessed 26 June 2017).

3. Product information Lewatit K 7333 . Available at: http://www.lenntech.com/Data- 
sheets/Lewatit-K-7333-L.pdf (accessed 26 June 2017).

4. Product information Lewatit MP 62 WS. Available at: http://www.lenntech.com/Datasheets/Lewatit-MP-62-WS-L.pdf (accessed 26 June 2017).

5. Kudryavtsev V.V. Patent RF, No 2217382, 2003.

6. Polyansky L.N. Patent RF, No 105284, 2011.

7. Polyansky L.N. Patent RF, No 134527, 2013.

8. Krysanov V.A. Patent RF, No 2355471, 2009.

Крысанов Вячеслав Александрович - доцент кафедры физической химии, к.Х.н., Воронежский государственный университет, Воронеж

Плотникова Наталья Викторовна - аспирант кафедры физической химии, Воронежский государственный университет, Воронеж.

Кравченко Тамара Александровна - профессор кафедры физической химии, д.Х.н., Воронежский государственный университет, Воронеж

Окушко Анастасия Игоревна - студент кафедры физической химии, Воронежский государственный университет, Воронеж.
9. Khorolskaya S.V., J. of Physical Chemistry, 2010, Vol. 88, No 5, p. 1-8

10.Kravchenko T.A., Polyansky L.N., Kalinichev A.I., Nanokompozity metallionoobmennik. M., Nauka Publ., 2009, 391 p.

11. Skoog D.A., Holler F. J., Nieman T. A. Principles of instrumental analysis. USA, Saunders College Pub., 1998, p. 1040.

12. Krysanov V.A. Patent RF, No 172363 , 2017.

13. Kipriyanova E.S., Kravchenko T.A., Konev D.V., J. of Physical Chemistry, 2010, Vol. 84, No 6, pp. 1104.

Krysanov Vyaceslav .A - Ph.D. (chemistry), associate prof., department of physical chemistry, Voronezh State University, Voronezh.

Plotnikova Nanatalya V. - the postgraduate student, department of physical and analytical chemistry, Voronezh State University, Voronezh.

Kravchenko Tamara A.- prof., grand Ph.D (chemistry), department of physical chemistry, Voronezh State University, Voronezh, email: krav280937@yandex.ru

Okushko Anastasiya I. - the student, department of physical and analytical chemistry, Voronezh State University, Voronezh. 